\title{
Study on Group Control Strategy of Multiple Elevators and Its Efficiency Evaluation
}

\author{
Lingyu Meng, Xing Zou, Tao Qu \\ College of Nuclear Technology and Automation Engineering, Chengdu University of Technology, Chengdu, China \\ Email: mxy_1995@sina.com
}

How to cite this paper: Meng, L.Y., Zou, X. and Qu, T. (2020) Study on Group Control Strategy of Multiple Elevators and Its Efficiency Evaluation. Open Access Library Journal, 7: e6410.

https://doi.org/10.4236/oalib.1106410

Received: May 9, 2020

Accepted: June 19, 2020

Published: June 22, 2020

Copyright $\odot 2020$ by author(s) and Open Access Library Inc.

This work is licensed under the Creative Commons Attribution International License (CC BY 4.0).

http://creativecommons.org/licenses/by/4.0/

(c) (i) Open Access

\begin{abstract}
With the rapid development of modern society, large buildings are springing up like mushrooms in every city. The huge passenger flow demands more and more intelligent buildings. The carrying capacity of cluster elevators is one of the important factors. The carrying efficiency of elevators directly determines whether the vertical traffic is crowded, whether the building is energy-saving and whether the building is intelligent. Therefore, the group control strategy of cluster elevator is very important. Firstly, the paper expounds the characteristics of elevator, introduces the configuration of software and hardware of Programmable Logic Controller (PLC) and the production and use of WinCC, in order to realize the program design of elevator control. Then, relying on the elevator simulation training system EET-2017035, three elevator group control algorithms are designed for the ten-story integrated office building equipped with six elevators, and five most common passenger flow modes are equipped according to the functions of the building. Three kinds of group control strategies are tested. Several cumulative indicators measured by simulation platform are used as evaluation indicators. After dealing with each indicator, evaluation functions are constructed. The evaluation values of three kinds of group control strategies in five-passenger flow modes are calculated, and the comparison of group control strategy algorithms is completed.
\end{abstract}

\section{Subject Areas \\ Mechanical Engineering}

\section{Keywords}

Elevator Control, PLC, Group Control, Elevator Traffic 


\section{Introduction}

\section{1) Research background}

Nowadays, for the public, the requirements of service indexes have been more and more. The study of the elevator in large buildings indicates that the key point of the elevator carrier systems is meeting the endurance physically and mentally for the passengers. However, in the theory, there are lots of group control strategies of cluster elevators, and various group control strategies have different carrying capacity and satisfaction of passengers. Besides, the strategies have different strengths, weaknesses, and application scenarios. For example, some group control strategies apply in the lower floor rather than upper and some apply in fewer stairs building rather than more stairs building. Consequently, aiming at some specific scenario, there will be a more suitable group control strategy relatively.

Aiming at different scale building, there will always be a better strategy in kinds of group control strategies of cluster elevators. Even though at the same building, the same is true in the different application scenarios and time. To appropriately choose the most suitable group control strategy, the experience of people and the carrying capacity of elevators in some time are not enough to assess. So, there should be a set of the entire assessment system. Jian Chen [1] took a series of accumulation as kernel potential variables of passenger satisfaction. This is similar to the construction of the efficiency indicator system of the elevator group control strategy. Focused on the different carrying environment and conditions, the quantitative analysis should be used to assess the quality of multiple group control strategies. So, the efficiency assessment is widely used.

\section{2) Research status of efficiency assessment}

For a relative and quantitative system efficiency, specific application scenarios and objectives should be considered. Assessment of system efficiency aims at design, analysis, optimization, and assessment. If in the management system, there are different symptoms and the indicators measured deviate from the default range, the relative indicators will change. According to the reasonable classification and definition of the range of the indicator, the levels of current assessment can be obtained [2].

With the analysis of multiple objective decisions, Jinwei Guo et al. [3] thought that the weight was affected by many factors, such as the effect of the subjective factors on the weight configuration, reasonable configuration proportion. Currently, there are a lot of ways to configure the weight. After normalization, the 5 -minute load factor was used as a significant reference to find the best elevator. Dongmei Song et al. [4] suggested an objective weighting method. The part of this method was based on the CARTTI method and entropy method and considered sufficiently the discreteness, correlation, and contrastive intension of data.

Shixin Gong et al. [5] found that if the failure model was assessed directly, the solution of the failure model would be invalid because the complete assessment system was lacked. Víctor Giménez [6] analyzed from 2 static and temporary perspectives to assess the total factor productivity (the hospital performance changing) 
in the whole time and the changing of its component. Referring to these components, it would help to define the variables and parameters in the system. For constructing the application scenario, it was a critical process.

\section{Elevator System Analysis}

\section{1) Elevator model introduction}

A traction elevator is a relatively complicated device. The elevator usually, from the structure, is divided into the elevator machine room, elevator shaft, lift car, lift hall, and so on. This paper aims at 6 ten-floor elevators model. The floors are composed of first-floor lobby supermarket, second and third floors mall, fourth and ninth-floor office, and tenth-floor lounge. The whole structure of the elevator simulation model is shown in Figure 1.

\section{2) Classification of elevator transportation modes}

When the elevator is working, the passenger flow is continuously changing. The most suitable group control scheduling algorithm can be chosen only by getting the passenger flow change and determining the elevator transportation modes. The ten floors medium comprehensive office building (the floors are composed of first-floor lobby supermarket, second and third floors mall, fourth and ninth-floor office, and tenth-floor lounge) is used as the research object in this design. Referring to the change of passenger flow in different time, the transportation mode is divided into 5 types: morning peak mode, lunch hour peak mode, afternoon peak mode, normal low passenger flow mode, and evening peak mode.

According to the scoring system of the simulation platform, shown as Figure 2, the following points will be composed as an assessment system.

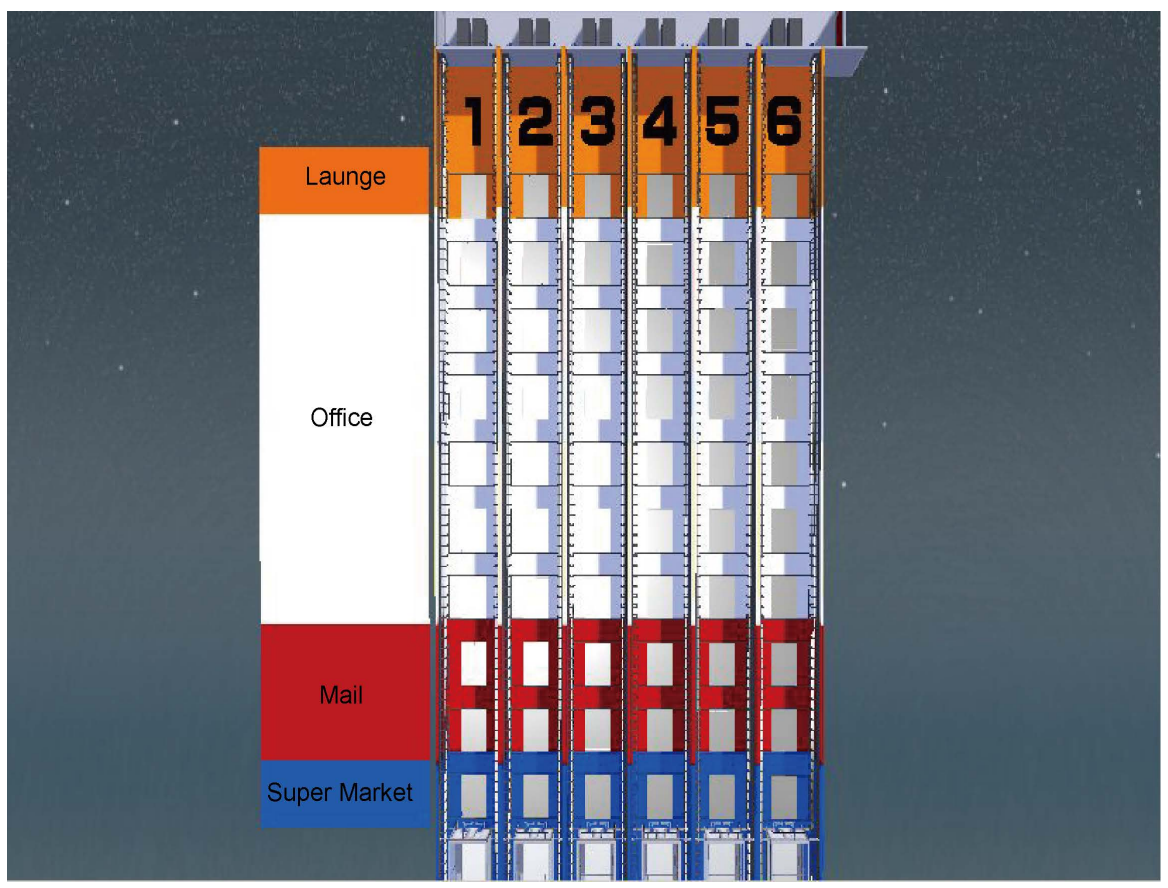

Figure 1. Entire structure of elevator simulation model. 


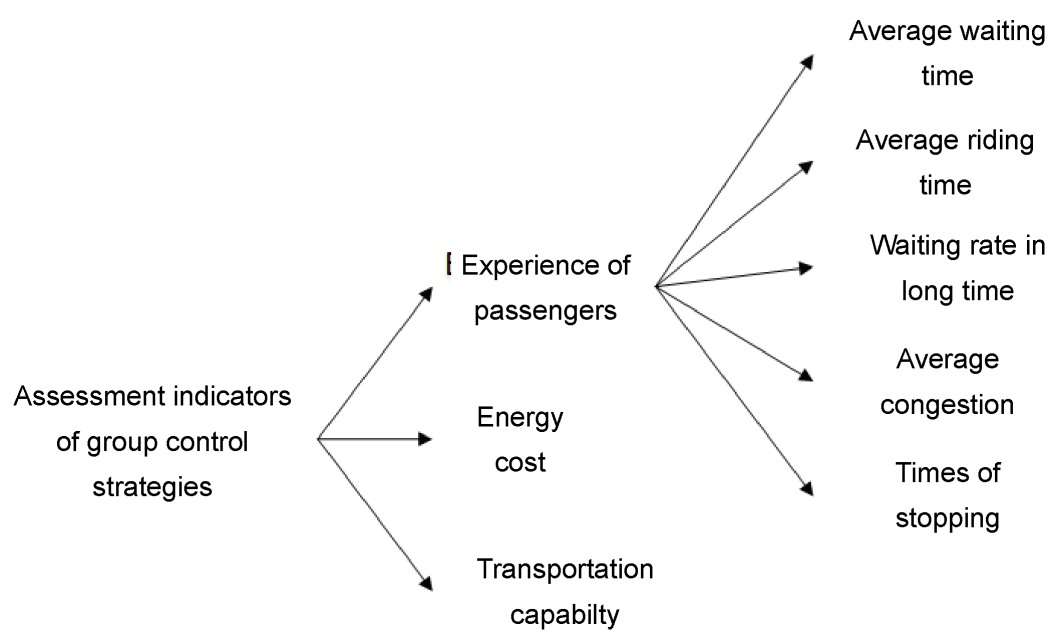

Figure 2. Assessment indicators of the group control algorithm.

\section{Design of Group Control Algorithm}

Multiple elevator group control systems will generally generate several assessment indicators referring to the different demands for building and passengers. There are several types of indicators and several factors in EGCS and the main object needs to intensify as much as possible; for the EGCS with more comprehensive considerations, the assessment standard is relatively higher. Conversely, when the consideration is less, the standard is relatively lower. In this design, several indicators will be used as consideration to analyze the multiple performance indicators and influence parameters of the EGCS. What's more, two methods have been determined: the shortest distance scheduling algorithm and minimum waiting time scheduling algorithm (in the following, they will be simplified as the shortest distance and minimum waiting time).

\subsection{The Shortest Distance Scheduling Algorithm}

The scheduling principle of this algorithm is that when there is a call, according to the evaluation function to calculate the distance between this floor and each elevator and to compare these distances, the call signal will allocate to the elevator with the shortest distance to the floor.

Because the floor distance between every floor is equal, the difference of floors can be used to replace the distance. The following factors should be considered in the shortest distance:

1) $N_{\text {OUT }}$ : Call floor

2) $N_{\text {CAR }}$ : The floor of the lift car

3) $N_{\text {ICAR }}:$ Improve the present floor

4) $N_{\mathrm{DIF}}$ : The floor distance

The up-call algorithm will be used as an example (the following is same).

\section{1) Calculating the real distance}

a) When the elevator goes up and the No. 1 elevator high-speed contactor is set 1 , the elevator is going up certainly and it will arrive on the upper floor soon. 
The improvement numbers of floors will be added 0.5, shown as Figure 3 .

$$
N_{\text {ICAR }}=N_{\text {CAR }}+0.5
$$

b) The absolute difference of floors will be calculated and that is to say the absolute distance between the call floor and lift car (Figure 4).

$$
N_{\text {DIF }}=\left|N_{\text {OUT }}-N_{\text {ICAR }}\right|
$$

\section{2) The floor difference adjustment}

Taking the No. 1 elevator as an example, if No. 1 elevator, at this time, is going down or up, but the real floors, at this time, are more than call-floors. This is a long time waiting situation, and it is not suitable to allocate. So 100 floors will be added to compare rather than calculating the precise difference of the floors, shown as Figure 5.

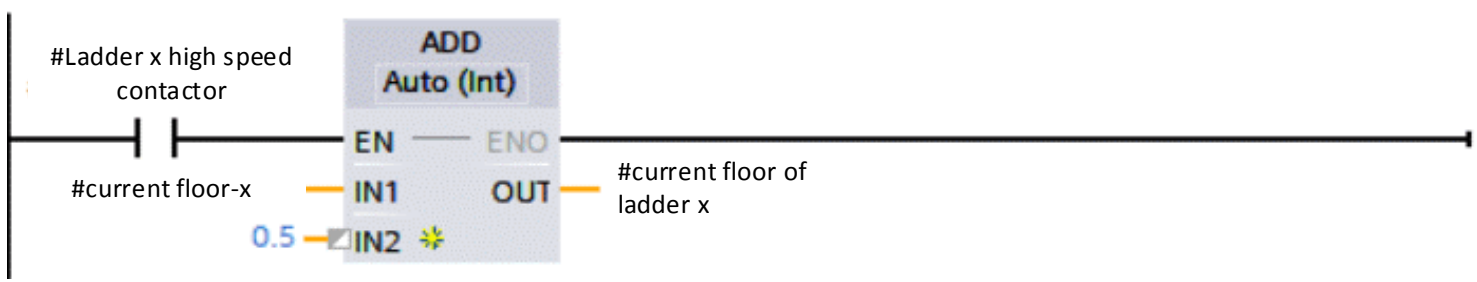

Figure 3. Floor solution with high speed.

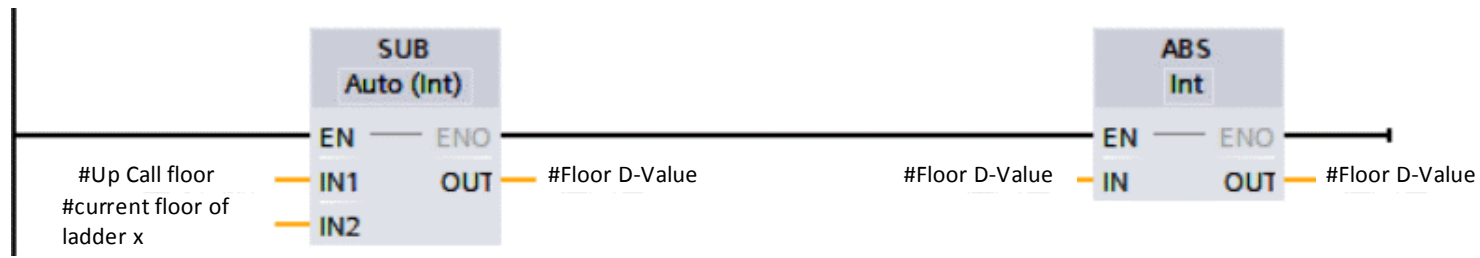

Figure 4. Difference calculation of real floors.

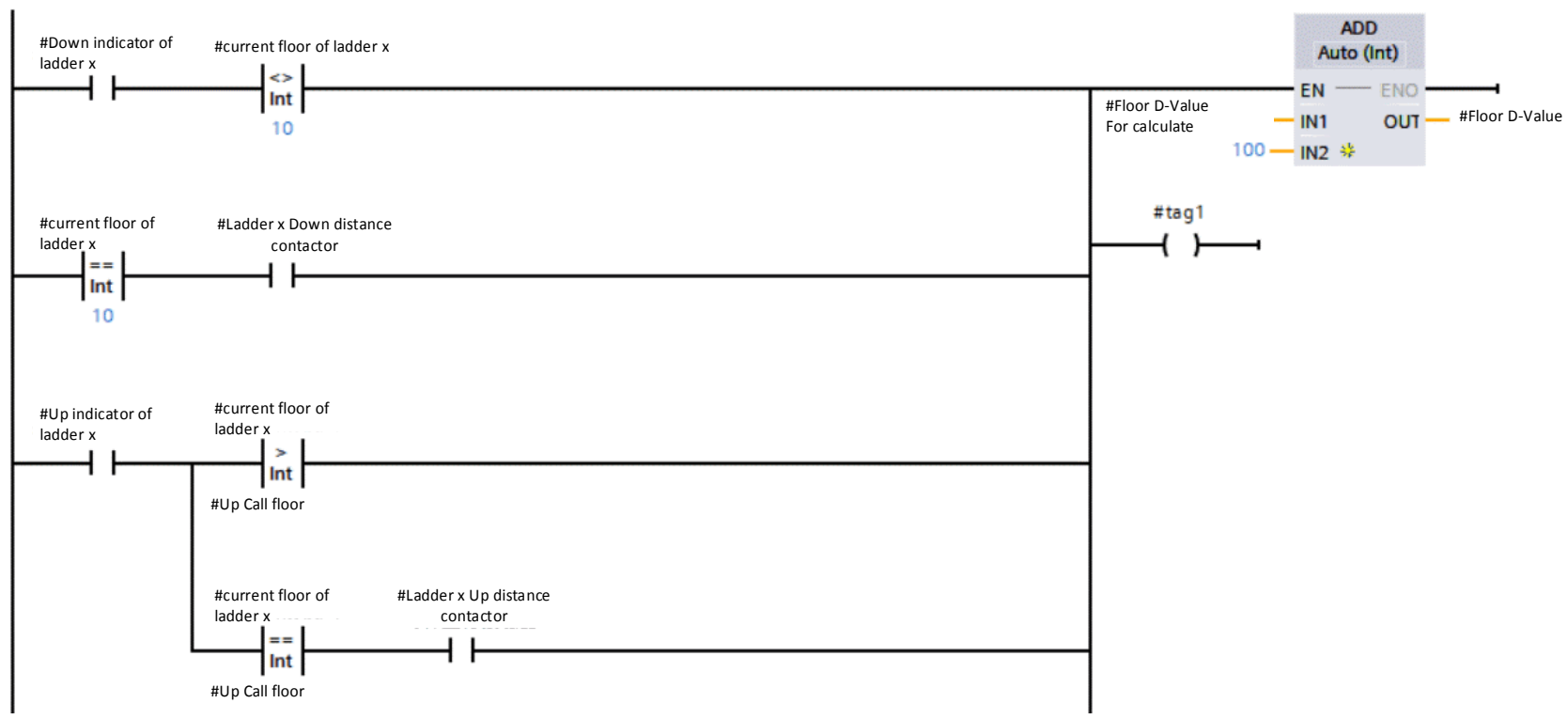

Figure 5. The floor difference adjustment. 


\subsection{The Minimum Waiting Time Scheduling Algorithm}

This algorithm needs to precisely calculate the uniform working velocity of the elevator and the time through one floor with uniform velocity. It needs to calculate each stopping time as well, including acceleration and deceleration, door opening and closing, and personnel entry and exit time. The speed of AC two speed elevators from start to stop is always constant, and the door opening and closing motor is DC motor, so the opening and closing time is also constant. The all above can be measured by the timer and the results are much precise. After analyzing every kind of factor, the multiple-object mathematical model will be built. And this model will be solved to find the best scheduling scheme. The following factors should be considered in the minimum waiting time:

1) $N_{\text {STOP }}$ : Number of the elevator stopping

2) $N_{\text {DIF }}$ : Difference between floors

3) $T_{\text {USP }}$ : Time to pass one floor with uniform velocity

4) $T_{\text {Stop }}$ : Time of stopping once

5) $T_{\text {ТОт }}$ : Total working time

6) $T_{\mathrm{TST}}$ : Total stopping time

7) $T_{\mathrm{EMP}}$ : False waiting time

8) $T_{\text {REL }}$ : Real waiting time

\section{1) Calculating the difference between the real floors}

a) As the same when the elevator goes up, and the No. 1 elevator high-speed contactor is set 1 , the elevator is going up certainly and it will arrive on the upper floor soon. The improvement numbers of floors will be added 0.5.

b) When the elevator goes up, and the No. 1 elevator high-speed contactor is set 0 , the elevator must be at leveling or arrives at leveling as soon. And at this time, nothing is added, shown as Figure 1. It is the same for the elevator goes down.

c) Calculation floors difference: it can be obtained by using call-floors subtracts the present floors. And then it is convenient to compare by taking the absolute value of the difference, shown as Figure 5.

2) Waiting time

$$
T_{\mathrm{EMP}}=T_{\mathrm{TOT}}+T_{\mathrm{TST}}
$$

a) Total working time

According to timing, the time of passing one floor with uniform velocity is $4 \mathrm{~s}$. Taking second-floor call-up as an example, if the second-floor call-up has been allocated to the No. 1 elevator when there is a call-up above the second floor again, the number of stopping should be added 1 .

Total working time calculation(s):

$$
T_{\mathrm{TOT}}=N_{\mathrm{DIF}} \times 4
$$

b) Total stopping time

According to timing, the time of each stopping is about $12 \mathrm{~s}$.

Total stopping time calculation(s):

$$
T_{\mathrm{TST}}=N_{\mathrm{STOP}} \times 12
$$




\section{3) Waiting time adjustment}

Taking the No. 1 elevator as an example, if the No. 1 elevator is going down or going up, but the real floors are more than call floors, this will be a long time waiting situation and it will not be suitable to allocate. So 10000 s will be added to compare rather than calculating the precise waiting time.

After calculation and comparison, the call will be allocated to the elevator of minimum waiting time.

\section{System Configuration and Efficiency Assessment}

The elevator control system consists of PLC S7-1214C, communication module, call-button, control loop, Three-phase AC asynchronous motor, LED digital tube, PC STATION/WINCC RT ADVANCE and so on, shown as Figure 6.

The Control system mainly includes a PLC host and power module (Table 1 and Figure 7).

Wincc and S7-1200CPU of PC, and the elevator simulation system were connected by the ProfiNET Industrial Ethernet. This would come into being an entire simulation process finishing on the coaxial cable.

\section{1) Passengers configuration}

The passenger table would be set and the test time was all 10 minutes (Table 2).

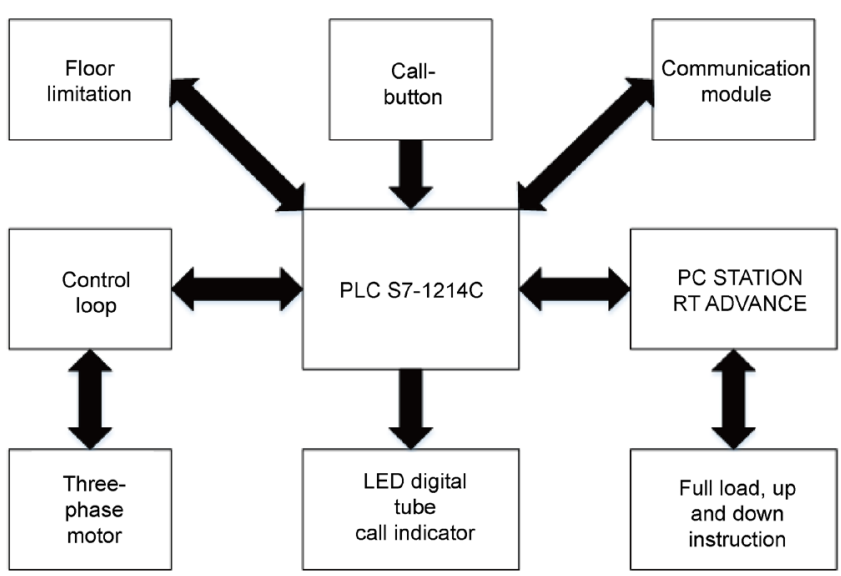

Figure 6. The structure diagram.

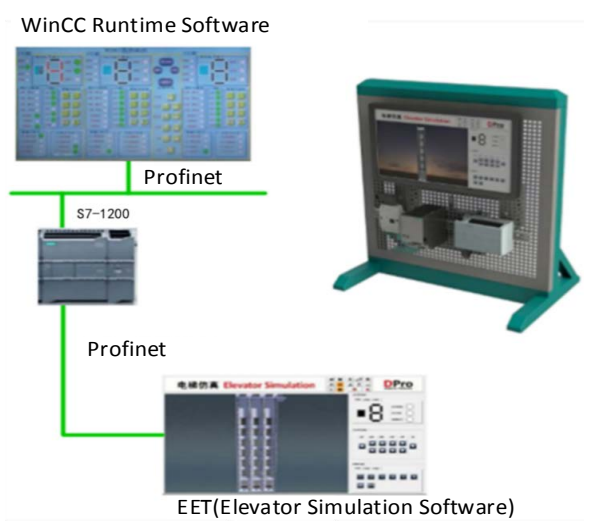

Figure 7. EET network topology. 
Table 1. Equipment selection table.

\begin{tabular}{cccc}
\hline Name & Type & Amount & Explanation \\
\hline CPU & S7-1200 CPU 1214C DC/DC/DC & 1 & Master controller \\
Power module & PM1207 & 1 & $\begin{array}{c}\text { Provide stable voltage } \\
\text { to master controller }\end{array}$ \\
$\begin{array}{c}\text { Ethernet } \\
\text { communication }\end{array}$ & ProfiNET cables and connectors & 1 & $\begin{array}{c}\text { Communicate with CPU } \\
\text { and GPU }\end{array}$ \\
\hline
\end{tabular}

Table 2. Passenger setting table.

\begin{tabular}{|c|c|c|c|c|c|c|c|}
\hline & Total passengers & $\begin{array}{l}\text { Number of } \\
\text { people from the } \\
\text { first floor to the } \\
\text { office }\end{array}$ & $\begin{array}{c}\text { Number of } \\
\text { exchanges } \\
\text { between floors }\end{array}$ & $\begin{array}{l}\text { Number of } \\
\text { people from the } \\
\text { office to the top } \\
\text { floor }\end{array}$ & $\begin{array}{l}\text { Number of } \\
\text { people from the } \\
\text { top floor to the } \\
\text { office }\end{array}$ & $\begin{array}{l}\text { Number of } \\
\text { people from the } \\
\text { office to the first } \\
\text { floor }\end{array}$ & $\begin{array}{l}\text { The range of } \\
\text { passengers } \\
\text { weight }(\mathrm{kg})\end{array}$ \\
\hline $\begin{array}{l}\text { Normal low } \\
\text { passenger flow }\end{array}$ & 100 & 8 & 79 & 4 & 7 & 2 & $49-88$ \\
\hline Moring peak & 200 & 161 & 30 & 3 & 2 & 4 & $49-88$ \\
\hline Lunch time peak & 200 & 1 & 20 & 171 & 3 & 5 & $49-88$ \\
\hline Afternoon peak & 200 & 5 & 27 & 3 & 164 & 1 & $49-88$ \\
\hline Evening peak & 200 & 4 & 28 & 2 & 3 & 163 & $49-88$ \\
\hline
\end{tabular}

\section{2) Weight configuration}

The weights of above 6 indicators are represented as $W_{1} \sim W_{6}$. The goal of the algorithm design in the elevator group control system is to achieve the shortest waiting time outside the hall, reduce the long waiting rate of passengers, shorten the travel of each elevator, allocate the elevator response reasonably, prevent the clustering and uneven busy and idle, so as to meet the requirements of comfort, safety and economy. However, there may be conflicts in the above conditions. For example, the pursuit of the minimum waiting time must cause a certain degree of energy loss. Therefore, this paper will be divided into two cases for weight distribution. It focuses on the psychological indicators of passengers and energy consumption indicators, and adopts the method of average distribution for non important influencing factors.

At the normal low passenger flow mode, the elevator will not overweight basically, because the passengers distributed on every floor are relatively less and the exchange of passengers is mainly between floors. Therefore, at this time, the energy conservation indicator will be considered significant and put at first [7]. At the peak mode, the first goal is transforming the passengers to the target floor quickly. At this time, the key indicators will be the average waiting time of passengers, ride time, and waiting rate in a long time. These indicators will directly affect the experience of passengers, so the energy cost will not be the first goal to consider. The weight configuration shows in Table 3. 


\section{3) Efficiency assessment results}

The above 6 indicators are represented as formulation:

$$
\begin{aligned}
S(i)= & W_{1} \frac{\min \left(A_{\mathrm{HT}}(i)\right)}{A_{\mathrm{HT}}(i)}+W_{2} \frac{\min \left(A_{\mathrm{CT}}(i)\right)}{A_{\mathrm{CT}}(i)}+W_{3} \frac{\min \left(P_{\mathrm{CHT}}(i)\right)}{P_{\mathrm{CHT}}(i)} \\
& +W_{4} \frac{\min \left(L_{\mathrm{YX}}(i)\right)}{L_{\mathrm{YX}}(i)}+W_{5} \frac{\min \left(T_{\mathrm{S}}(i)\right)}{T_{\mathrm{S}}(i)}+W_{6} \frac{T_{\mathrm{A}}(i)}{\max \left(T_{\mathrm{A}}(i)\right)}
\end{aligned}
$$

The indicator parameters show as Table 4 and all the maximum and minimum indicators are the indicators of the best reference model.

The test results of 6 cumulative amounts in the simulation platform are taken into the evaluation function to calculate. The calculation results are shown as follow Table 5.

The assessment result will be shown in a histogram to compare the assessment indicators conveniently and directly, shown as Figure 7. But these 6 indicators are different in unit and order of magnitude, the data in the figure are all the result of normalization.

2) Lunch hour peak mode (Table 6)

3) Afternoon peak mode (Table 7)

4) Normal low passenger flow mode (Table 8)

5) Evening peak mode (Table 9)

Table 3. Weight configuration table.

\begin{tabular}{ccccccc}
\hline & $W_{1}$ & $W_{2}$ & $W_{3}$ & $W_{4}$ & $W_{5}$ & $W_{6}$ \\
\hline Low passenger flow & 0.2 & 0.1 & 0.1 & 0.2 & 0.2 & 0.2 \\
Peak mode & 0.2 & 0.2 & 0.2 & 0.1 & 0.1 & 0.2 \\
\hline
\end{tabular}

Table 4. Indicator parameters.

\begin{tabular}{cccc}
\hline Indicators & Meaning & Indicators & Meaning \\
\hline$A_{\mathrm{HT}}(i)$ & Average waiting time & $\min \left(A_{\mathrm{HT}}(i)\right)$ & Minimumaverage waiting time \\
$A_{\mathrm{CT}}(i)$ & Average riding time & $\min \left(A_{\mathrm{CT}}(i)\right)$ & Shortest riding time \\
$P_{\mathrm{CHT}}(i)$ & Waiting rate in a long time & $\min \left(P_{\mathrm{CHT}}(i)\right)$ & Minimum waiting rate in long time \\
$L_{\mathrm{YX}}(i)$ & Total distance & $\min \left(L_{\mathrm{YX}}(i)\right)$ & Shortest total distance \\
$T_{\mathrm{S}}(i)$ & Times of stopping & $\min \left(T_{\mathrm{S}}(i)\right)$ & Minimum times of stopping \\
$T_{\mathrm{A}}(i)$ & Number of transporting passengers & $\max \left(T_{\mathrm{A}}(i)\right)$ & Maximum number of transporting passengers \\
\hline
\end{tabular}

Table 5. The assessment result of morning peak mode.

\begin{tabular}{cccccccc}
\hline Algorithm & $\begin{array}{c}\text { Average waiting } \\
\text { time/s }\end{array}$ & $\begin{array}{c}\text { Averageriding } \\
\text { time/s }\end{array}$ & $\begin{array}{c}\text { Waiting rate in } \\
\text { long time/\% }\end{array}$ & Total distance/m & $\begin{array}{c}\text { Times of } \\
\text { stopping }\end{array}$ & $\begin{array}{c}\text { Number of } \\
\text { transporting } \\
\text { passengers }\end{array}$ & $S(i)$ \\
Shortest distance & 52.05 & 86.08 & 0.27 & 755.65 & 239 & 162 & 0.84 \\
Minimum waiting time & 42.50 & 86.56 & 0.27 & 796.39 & 254 & 155 & 0.85 \\
\hline
\end{tabular}


Table 6. The assessment result of lunch hour peak mode.

\begin{tabular}{cccccccc}
\hline Algorithm & $\begin{array}{c}\text { Average waiting } \\
\text { time/s }\end{array}$ & $\begin{array}{c}\text { Average riding } \\
\text { time/s }\end{array}$ & $\begin{array}{c}\text { Waiting rate in } \\
\text { long time/\% }\end{array}$ & Total distance/m & $\begin{array}{c}\text { Times of } \\
\text { stopping }\end{array}$ & $\begin{array}{c}\text { Number of } \\
\text { transporting } \\
\text { passengers }\end{array}$ & $\begin{array}{c}S(i) \\
\text { p }\end{array}$ \\
Shortest distance & 51.67 & 84.07 & 0.21 & 799.32 & 259 & 182 & 0.89 \\
Minimum waiting time & 49.21 & 82.42 & 0.21 & 811.05 & 260 & 185 & 0.91 \\
\hline
\end{tabular}

Table 7. The assessment result of afternoon peak mode.

\begin{tabular}{cccccccc}
\hline Algorithm & $\begin{array}{c}\text { Average waiting } \\
\text { time/s }\end{array}$ & $\begin{array}{c}\text { Average riding } \\
\text { time/s }\end{array}$ & $\begin{array}{c}\text { Waiting rate in } \\
\text { long time/\% }\end{array}$ & Total distance/m & $\begin{array}{c}\text { Times of } \\
\text { stopping }\end{array}$ & $\begin{array}{c}\text { Number of } \\
\text { transporting } \\
\text { passengers }\end{array}$ & $S(i)$ \\
Shortest distance & 42.04 & 66.08 & 0.24 & 729.22 & 217 & 154 & 0.88 \\
Minimum waiting time & 60.46 & 65.66 & 0.4 & 849.77 & 240 & 164 & 0.75 \\
\hline
\end{tabular}

Table 8. The assessment result of normal low passenger flow mode.

\begin{tabular}{|c|c|c|c|c|c|c|c|}
\hline Algorithm & $\begin{array}{c}\text { Average waiting } \\
\text { time } / \mathrm{s}\end{array}$ & $\begin{array}{c}\text { Average riding } \\
\text { time } / \mathrm{s}\end{array}$ & $\begin{array}{l}\text { Waiting rate in } \\
\text { long time/\% }\end{array}$ & Total distance $/ \mathrm{m}$ & $\begin{array}{l}\text { Times of } \\
\text { stopping }\end{array}$ & $\begin{array}{l}\text { Number of } \\
\text { transporting } \\
\text { passengers }\end{array}$ & $S(i)$ \\
\hline Shortest distance & 43.37 & 54.66 & 0.17 & 370.43 & 139 & 91 & 0.88 \\
\hline Minimum waiting time & 34.61 & 51.34 & 0.17 & 401.81 & 142 & 90 & 0.89 \\
\hline
\end{tabular}

Table 9. The assessment result of evening peak mode.

\begin{tabular}{cccccccc}
\hline Algorithm & $\begin{array}{c}\text { Average waiting } \\
\text { time/s }\end{array}$ & $\begin{array}{c}\text { Average riding } \\
\text { time/s }\end{array}$ & $\begin{array}{c}\text { Waiting rate in } \\
\text { long time/\% }\end{array}$ & Total distance/m & $\begin{array}{c}\text { Times of } \\
\text { stopping }\end{array}$ & $\begin{array}{c}\text { Number of } \\
\text { transporting } \\
\text { passengers }\end{array}$ & $S(i)$ \\
Shortest distance & 51.67 & 84.07 & 0.21 & 799.32 & 259 & 182 & 0.89 \\
Minimum waiting time & 50.01 & 82.08 & 0.24 & 808.22 & 262 & 185 & 0.87 \\
\hline
\end{tabular}

\section{Conclusions}

According to the calculation, the assessment value of 2 group control strategies can be obtained in 5 passenger flow modes. The results are as follow:

1) In the 5 passenger flow modes, the assessment values of the shortest distance and minimum time are very close to each other. And the latter is slightly higher than the former because the total working time and total stopping time were considered accurately in the minimum time. Compared to the former, the consideration was more specific.

2) In the normal flow passenger low mode, it is similar for the energy conservation indicators of 2 type group control strategies and the assessment results are similar too. Because, at this time, the energy conservation indicator takes more proportion, and other indicators are weakened. The advantages of group control strategies cannot appear easily.

3) In this design, aiming at the morning peak mode, the most representative mode, in the 5 passenger flow modes, the number of transporting the passengers measured in this mode is not ideal, because this is to be more in line with reality. 
The type of passenger was set as No Patient, and they would leave when the waiting time was so long. So this would lose some passengers and make the number of transporting passengers to be lower than other conditions.

To sum up, the scheduling algorithm of the minimum waiting time is the best, and one of the highlights of the algorithm is: in the peak passenger flow, such as class peak, as long as it is in the peak state, the first floor passengers do not need to press the up call button, the elevator will also give priority to alleviate the first floor congestion.

\section{Conflicts of Interest}

The authors declare no conflicts of interest regarding the publication of this paper.

\section{References}

[1] Chen, J., Tang, W., Cai, X.Y., et al. (2018) Multi Group Structural Equation Model of Passenger Satisfaction of Urban Rail Transit. Transportation System Engineering and Information, 18, 173-178.

[2] Bai, S.H., Ma, J.Y. and Lv, S.W. (2004) The Effectiveness Evaluation of Control Center System Based on Neural Network. Telecommunication Technology, 44, 125-128.

[3] Guo, J.W., Pu, X.Q. and Gao, X. (2014) An Improved Weight Calculation Method of Multi-Objective Decision-Making Index. Journal of Xi an University of Electronic Science and Technology, 41, 118-125.

[4] Song, D.M., Liu, C.X. and Shen, C. (2015) Multi Objective and Multi-Attribute Decision Making Method Based on Subjective and Objective Weighting Method. Journal of Shandong University (Engineering Edition), 45, 1-9.

[5] Gong, S.X., Shao, C. and Zhu, L. (2017) Energy Efficiency Evaluation Based on DEA Integrated Factor Analysis in Ethylene Production. Chinese Journal of Chemical Engineering, 25, 793-799. https://doi.org/10.1016/j.cjche.2016.10.023

[6] Giménez, V., Prieto, W., Prior, D. and Tortosa-Ausina, E. (2019) Evaluation of Efficiency in Colombian Hospitals: An Analysis for the Post-Reform Period. Socio-Economic Planning Sciences, 65, 20-35. https://doi.org/10.1016/j.seps.2018.02.002

[7] Fu, M. and Han, M. (2015) Simulation of Elevator Group Control System Based on Multi Rule Weighting. Computer and Digital Engineering, 7, 1249-1251. 